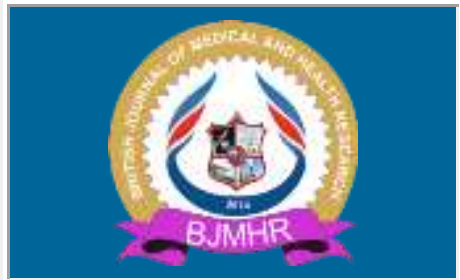

\title{
BJMHR
}

British Journal of Medical and Health Research Journal home page: www.bjmhr.com

\section{Interaction of Methylglyoxal with Alpha-Lactalbumin, Beta- Lactoglobulin and Alpha S casein - A Comparative Study.}

\author{
Jaya Bhattacharyya \\ Department of Biophysics, Molecular Biology \& Bioinformatics, University of Calcultta, \\ 92 Acharya Prafulla Chandra Road, Kolkata 700009.
}

\section{ABSTRACT}

Methylglyoxal (MG) is a highly reactive alpha-oxoaldehyde, which increases under diabetic condition. It is known to form Advanced Glycation Endproducts (AGEs) by non-enzymatic glycation following the Maillard reaction. The nature of interaction of methylglyoxal, with milk proteins - alpha-lactalbumin (with substantial amounts of alpha helix, beta sheet and random coil), beta lactoglobulin (a major beta sheeted protein) and alpha $\mathrm{S}$ casein (a random coiled protein) have been studied using different spectroscopic techniques at low concentrations ranging from 0-20 micromolar. All the three milk proteins (10 micromolar) in absence and presence of methylglyoxal are incubated at $25^{\circ} \mathrm{C}$ for 3 and 6 days. UV absorption study indicates that methylglyoxal lowers the scattering above $300 \mathrm{~nm}$ observed for all the milk proteins compared to control. Fluorescence studies show that the intrinsic tryptophan fluorescence peak intensity increases upon incubation with methylglyoxal with all the three proteins but the tryptophan peak shifts to lower wavelengths only in case of beta lactoglobulin and alpha S casein. Slight decrease in the ANS fluorescence intensity is observed upon methylglyoxal binding to alpha lactalbumin and beta lactoglobulin whereas we see a slight increase in the intensity with alpha S casein. Far-UV CD spectra reveal that upon incubation of the milk proteins with methylglyoxal, the proteins tend to regain its secondary structure than controls (which were incubated under similar conditions in absence of methylglyoxal) and it is more pronounced in case of beta lactoglobulin and alpha $\mathrm{S}$ casein than alpha lactalbumin. Methylglyoxal reduces the hydrodynamic diameter of the proteins thereby increasing the compactness of the proteins. All the above studies indicate that methylglyoxal improves the stability of the proteins.

*Corresponding Author Email: jayab_mypdfs@yahoo.com

Received 18 October 2019, Accepted 04 November 2019

Please cite this article as: Bhattacharyya $\mathrm{J}$ et al., Interaction of Methylglyoxal with Alpha-Lactalbumin, Beta-Lactoglobulin and Alpha S casein - A Comparative Study . British Journal of Medical and Health Research 2019. 


\section{INTRODUCTION}

Methylglyoxal (MG) is a glycating agent produced non-enzymatically during the glycolytic pathway (1). Concentration of methylglyoxal increases during diabetic conditions (2). It is known to modify macromolecules specially proteins and DNA in tissues and plasma. Under hyperglycaemic conditions, different proteins like, insulin (3), myoglobin (4), hemoglobin (5), serum albumin (6) gets glycated and over time forms Advanced Glycation End products (AGES). Harmful effects of sugar metabolites during diabetes and other AGE related diseases are well known (3). There are also reports that high concentrations of methylglyoxal stabilize protein and other macromolecules (3-6) in vitro and prevent aggregation of proteins.

Milk comprise mainly of casein. The whey proteins like $\alpha$-lactalbumin (ALA) and $\beta$ lactoglobulin (BLG) also form a major part of the milk composition (7). Structural organization of proteins influences their binding behavior with alpha oxoaldehydes. For instance, we have seen that binding of glyoxal to hemoglobin (with well-defined quaternary structural organization) is markedly different from that of myoglobin (with well-defined tertiary structural organization) (8). We therefore became interested to investigate whether there is any difference in the binding modality of methylglyoxal (MG) with different conformational states of proteins viz the $\alpha$-helical, $\beta$-sheeted or the random coiled states. For this purpose we have chosen the following milk proteins for our study: $\alpha$-lactalbumin or ALA (containing substantial amounts of $\alpha$-helix, $\beta$-sheet and random coil), $\beta$-lactoglobulin or BLG (a predominantly $\beta$-sheet protein) and $\alpha_{S}$-casein or CAS (mostly random coiled protein). In this study, we report our results on the nature of binding of the sugar metabolite with the milk proteins.

\section{MATERIALS AND METHOD}

\section{Materials:}

Alpha lactalbumin (ALA), beta lactoglobulin (BLG), alpha S casein (CAS), methylglyoxal (MG) were purchased from Sigma. All other chemicals were purchased from local company and are of analytical grade.

\section{Preparation of protein solutions and methylglyoxal:}

All protein solutions were made fresh in $10 \mathrm{mM}$ phosphate buffer, $\mathrm{pH}$ 7.0. Concentrations of the milk proteins (alpha lactalbumin : $\varepsilon_{280 \mathrm{~nm}}=28,540 \mathrm{M}^{-1} \mathrm{~cm}^{-1}$, beta lactoglobulin : $\varepsilon_{280 \mathrm{~nm}}=$ $17,600 \mathrm{M}^{-1} \mathrm{~cm}^{-1}$, $\alpha_{\mathrm{S}}$-casein $\mathrm{E}_{1 \%, 280}=10.1$ ) were determined spectrophotometrically from their respective molar extinction coefficients. MG was also made fresh and diluted in the same buffer and the concentration of MG was determined spectrophotometrically using an exctinction coefficient of $\varepsilon_{284 \mathrm{~nm}}=12.3 \mathrm{M}^{-1} \mathrm{~cm}^{-1}(9)$.

\section{Absorption and fluorescence spectroscopy:}


Methylglyoxal (MG) at a dose and time dependent manner was incubated with milk proteins alpha lactalbumin (ALA), beta lactoglobulin (BLG) and alpha $\alpha \mathrm{S}$ casein (CAS). Briefly, methylglyoxal $(\mathrm{MG})$ at different concentrations ranging from 0 to $20 \mu \mathrm{M}$ were incubated at room temperature $\left(25^{\circ} \mathrm{C}\right)$ with a fixed concentration $(10 \mu \mathrm{M})$ of the proteins for 3 or 6 days. Excess methylglyoxal is then removed from the mixture by repeated dialysis in $10 \mathrm{kDa}$ cutoff filter before acquisition of absorption, fluorescence or CD spectra. Experiments have been repeated thrice before confirming the results. For UV absorption spectra, samples were scanned from 240-440 $\mathrm{nm}$ in Shimadzu UV2401PC spectrophotometer and for acquisition of tryptophan fluorescence spectra both treated and untreated samples were excited at $295 \mathrm{~nm}$ and emission scanned from 310 to $410 \mathrm{~nm}$. Slit widths were kept at $5 \mathrm{~nm}$ each. Fluorescence experiments were done in a Horiba Fluoromax 4 spectrofluorimeter.

\section{Far-UV Circular Dichroism studies:}

Acquisition of far-UV circular dichroic spectra was done in a Jasco 815 spectropolarimeter in the range $200-250 \mathrm{~nm}$ for milk proteins in absence and presence of methylglyoxal incubated at r.t. for 6 days.

\section{ANS Binding assay:}

$10 \mu \mathrm{M}$ of unmodified and sugar metabolite-modified milk proteins were incubated separately with 20-fold molar excess of ANS for $1 \mathrm{~h}$ at r.t. To this ANS bound samples, methylglyoxal and glyoxal at a concentration of $20 \mu \mathrm{M}$ were added separately. Fluorescence emission spectra of the samples were recorded between 390 and $600 \mathrm{~nm}$ in Horiba Fluoromax 4 spectrofluorimeter at $25^{\circ} \mathrm{C}$ with excitation and emission band passes of $5 \mathrm{~nm}$ each. ANS emission was measured after excitation at $350 \mathrm{~nm}$.

\section{Dynamic Light Scattering (DLS) studies:}

Dynamic light scattering studies were conducted in a Brookhaven DLS machine for methylgyoxal incubated and non-incubated milk proteins incubated at r.t. for 6 days. Changes in diameter of the proteins were measured due to interaction with methylglyoxal.

\section{RESULTS AND DISCUSSION}

\section{Spectroscopic studies}

Figure 1 shows the absorption of spectra of different concentrations of methylglyoxal incubated with alpha lactalbumin, beta lactoglobulin and alpha $\mathrm{S}$ casein for 3 days. There is slight decrease in the absorption spectra of alpha lactalbumin when incubated with methylglyoxal for 3 or 6 days. On the other hand, beta lactoglobulin and alpha S-casein show significant decrease in the absorption spectral profile upon binding to methylglyoxal. Most importantly we notice, for all the three proteins, methylglyoxal seem to lower the scattering noticed above $300 \mathrm{~nm}$ compared to when the proteins are incubated for the same time without the sugar metabolite. 
Methylglyoxal presumably lowers the scattering by reducing the aggregation of the proteins when incubated at r.t. Significant change in the UV-absorption spectra is observed upon incubation of the proteins alone at r.t. for 3 or 6 days indicating aggregation of the proteins (data not shown). The UV-spectral profile of the proteins drastically improves upon incubation with methylglyoxal which indicates that the alpha oxoaldehyde probably stabilizes the proteins.

ALA

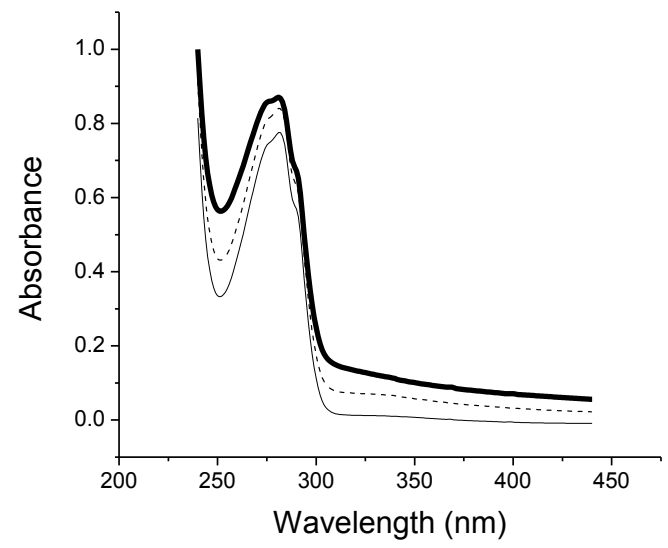

BLG

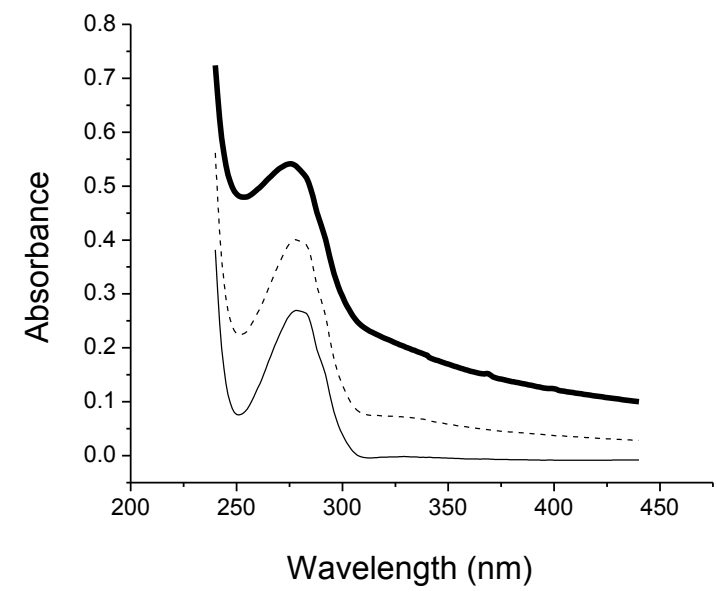

CAS

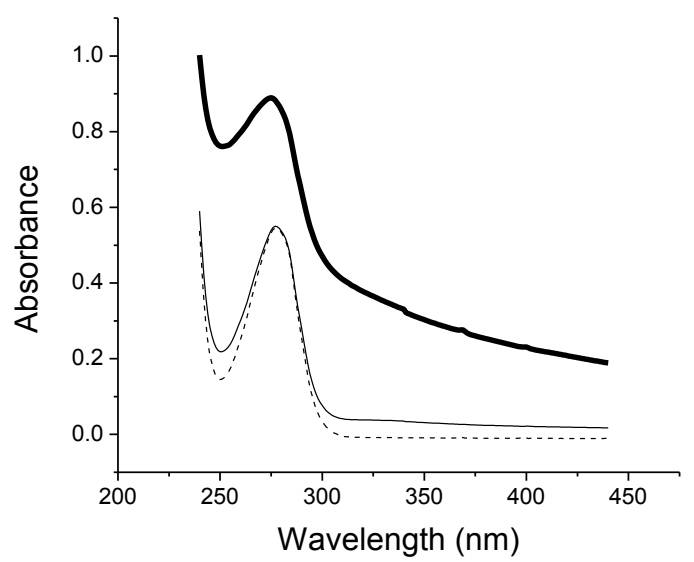

Figure 1: UV spectra of $10 \mu \mathrm{M}$ alpha lactalbumin (ALA,), beta lactoglobulin (BLG) and alpha $S$ casein (CAS) incubated with $0 \mu \mathrm{M}$ MG

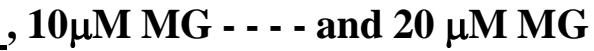



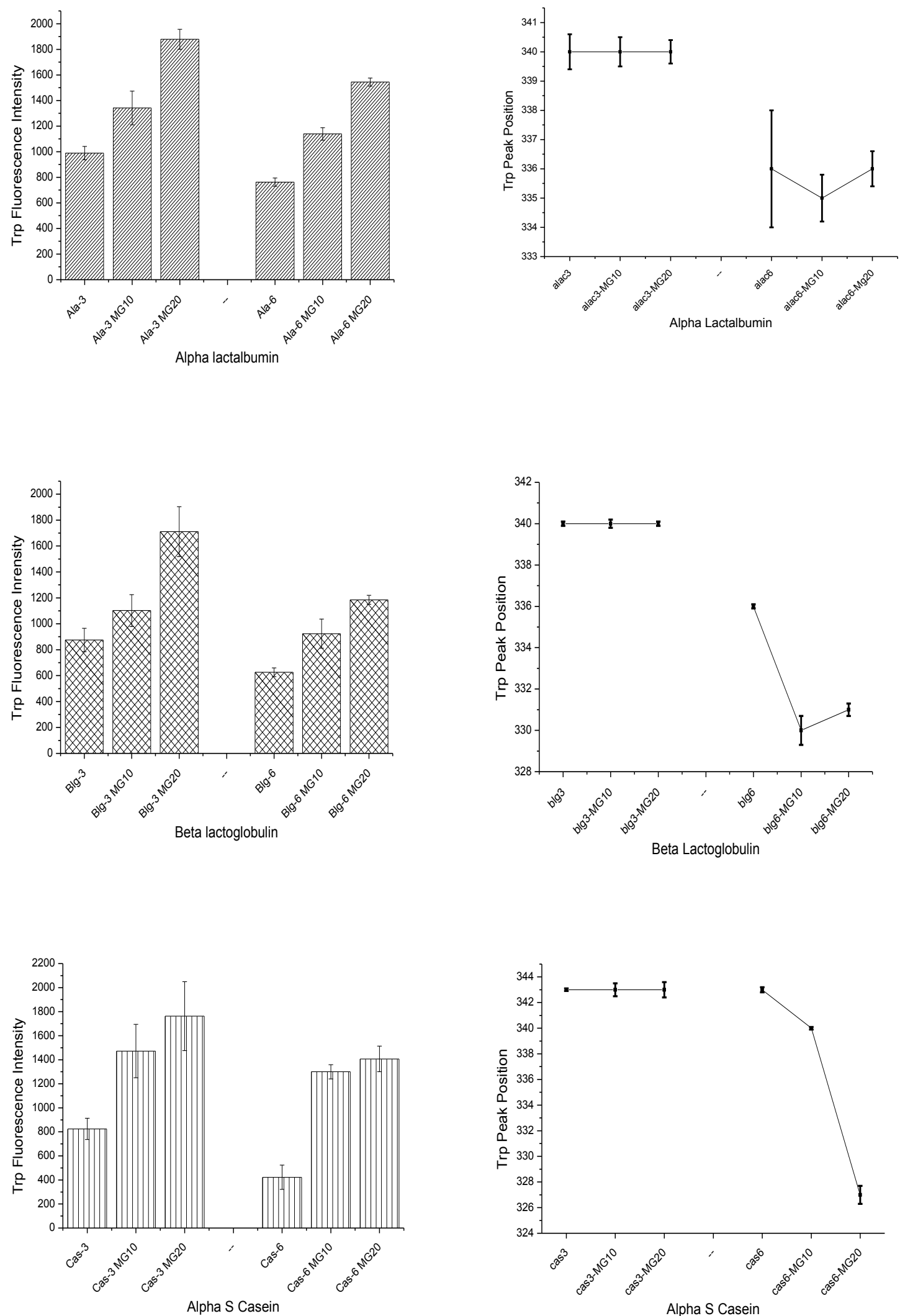

Figure 2: Tryptophan fluorescence peak intensity changes and tryptophan peak position changes. 
$10 \mu \mathrm{M}$ ALA incubated for 3 days without MG (Ala3), +10 $\mu$ M MG (Ala3-MG10), $+20 \mu M$ MG (Ala3-MG20).

$10 \mu \mathrm{M}$ ALA incubated for 6 days without MG (Ala6), +10 $\mu$ M MG (Ala6-MG10), $+20 \mu M$ MG (Ala6-MG20).

$10 \mu \mathrm{M}$ BLG incubated for 3 days without MG (Blg3), +10 $\mu \mathrm{M}$ MG (Blg3-MG10), +20 $\mu \mathrm{M}$ MG (Blg3-MG20).

$10 \mu \mathrm{M}$ BLG incubated for 6 days without MG (Blg6), +10 $\mu$ M MG (Blg6-MG10), +20 $\mu \mathrm{M}$ MG (Blg6-MG20).

10 $\mu \mathrm{M}$ CAS incubated for 3 days without MG (Cas3), +10 $\mu \mathrm{M}$ MG (Cas3-MG10), $+20 \mu \mathrm{M}$ MG (Cas3-MG20).

$10 \mu \mathrm{M}$ CAS incubated for 6 days without MG (Cas6), $+10 \mu M$ MG (Cas6-MG10), $+20 \mu M$ MG (Cas6-MG20).

Figure 2 shows the intrinsic tryptophan fluorescence intensities and tryptophan peak position changes of the proteins incubated with methylglyoxal for 3 and 6 days. Interestingly, the intrinsic fluorescence peak intensity of all the three milk proteins decreases gradually upon incubation at r.t. with time in absence of methylglyoxal (data not shown). Upon interaction with methylglyoxal, the intrinsic fluorescence intensity increases for all the three proteins suggesting that the tryptophan moieties assume a better conformational stability so as to increase the fluorescence quantum yield of the proteins. In case of alpha lactalbumin, methylglyoxal does not change the tryptophan peak position for the protein while in case of beta lactoglobulin and alpha $S$ casein, noticeable blue shift in tryptophan peak position of the proteins is observed. It indicates that the tryptophan moieties of the protein molecules in case of beta lactoglobulin and alpha $\mathrm{S}$ casein are sequestered into a more hydrophobic environment thereby creating a more compact structure for the proteins compared to alpha lactalbumin. 

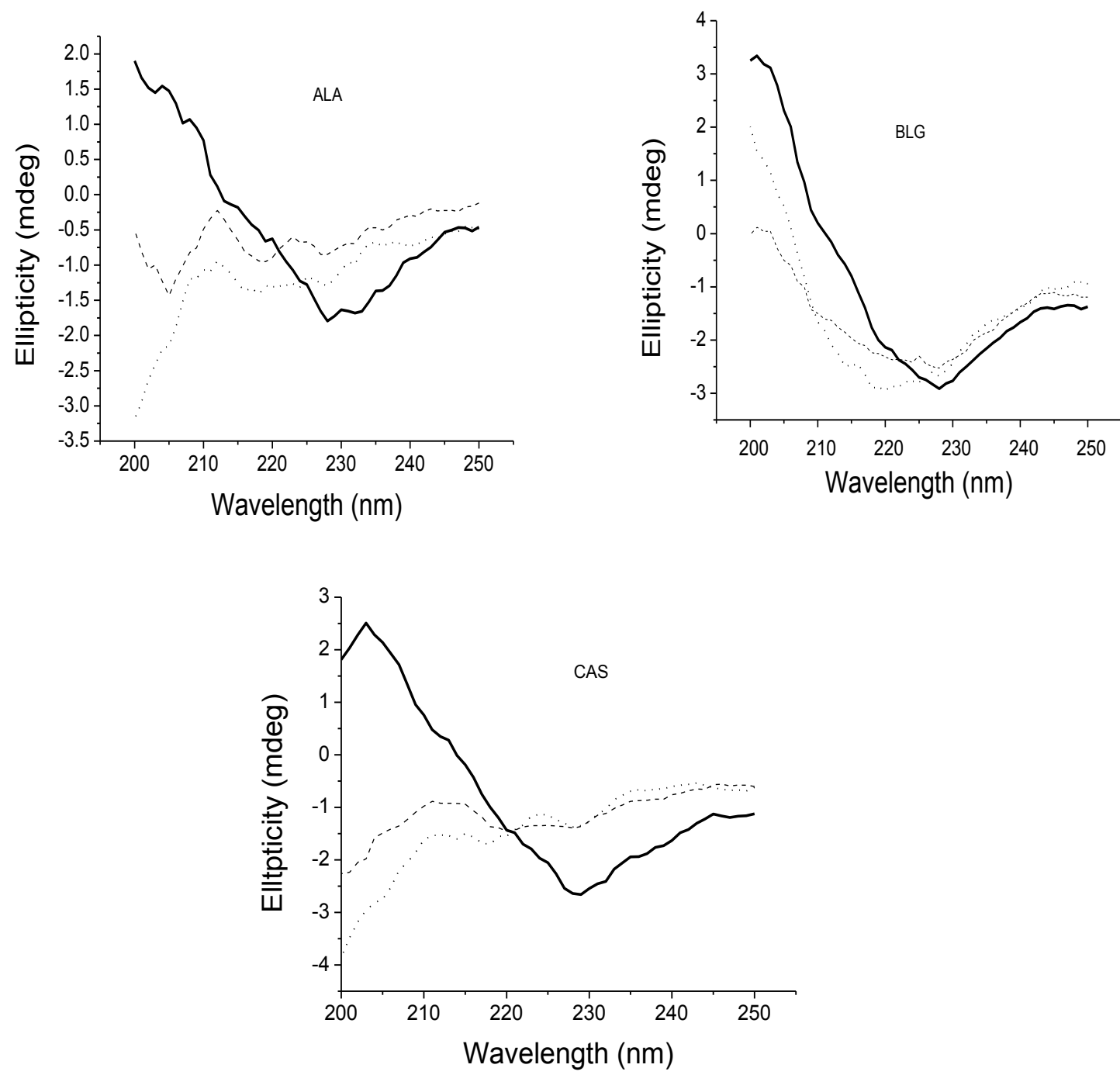

Figure 3: Far-UV CD spectra of ALA $(10 \mu \mathrm{M})$, BLG $(10 \mu \mathrm{M})$, and CAS $(10 \mu \mathrm{M})$ incubated with $0 \mu \mathrm{M}$ MG

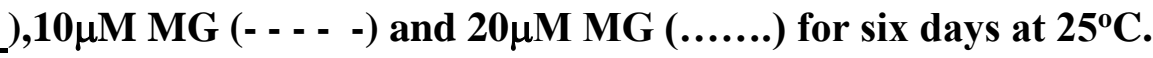
Figure 3 shows the far-UV circular dichroic spectra of the milk proteins upon binding to methylglyoxal. It is known that the all the three milk proteins have their characteristic secondary structures. Alpha lactalbumin has a predominant alpha helical structure along with substantial amounts of random coil and small amount of beta sheet. Beta lactoglobulin has a predominantly beta sheet structure under native conditions and alpha $\mathrm{S}$ casein is mostly random coiled in the native form. From the figure, it is evident that the secondary structures of all the milk proteins after incubation at r.t for 6 days without the sugar metabolites show negative ellipticity at $230 \mathrm{~nm}$ indicative of aggregation of both the proteins towards a more fibrillar form (10). Alteration in the secondary structural properties of the milk proteins occurs upon incubation of the milk proteins with methylglyoxal. Methylglyoxal causes alpha lactalbumin to assume a more random coiled structure with little bit helicity upon binding. Six days methylglyoxal incubated beta lactoglobulin acquires more beta pleated sheet structure (negative elliptical peak around $218 \mathrm{~nm}$ ) with concomitant decrease in the negative peak at 230 $\mathrm{nm}$. Whereas in case of alpha $\mathrm{S}$ casein, we notice that the aggregated protein acquires a more www.bjmhr.com 
native random coiled conformation. It is therefore apparent that methylglyoxal tends to improve the stability of the secondary structural characteristics of all the milk proteins from an aggregated fibrillar conformation to a preferably stable secondary structural conformation.

ANS has been widely used as a fluorescent dye to measure the amount of surface hydrophobicity in proteins and peptides $(11,12)$. The binding of the probe to the proteins results in a shift in the fluorescence emission maximum of the dye to lower wavelengths, with simultaneous increase in the fluorescence intensity attributing to the presence of solvent accessible hydrophobic patches in proteins.
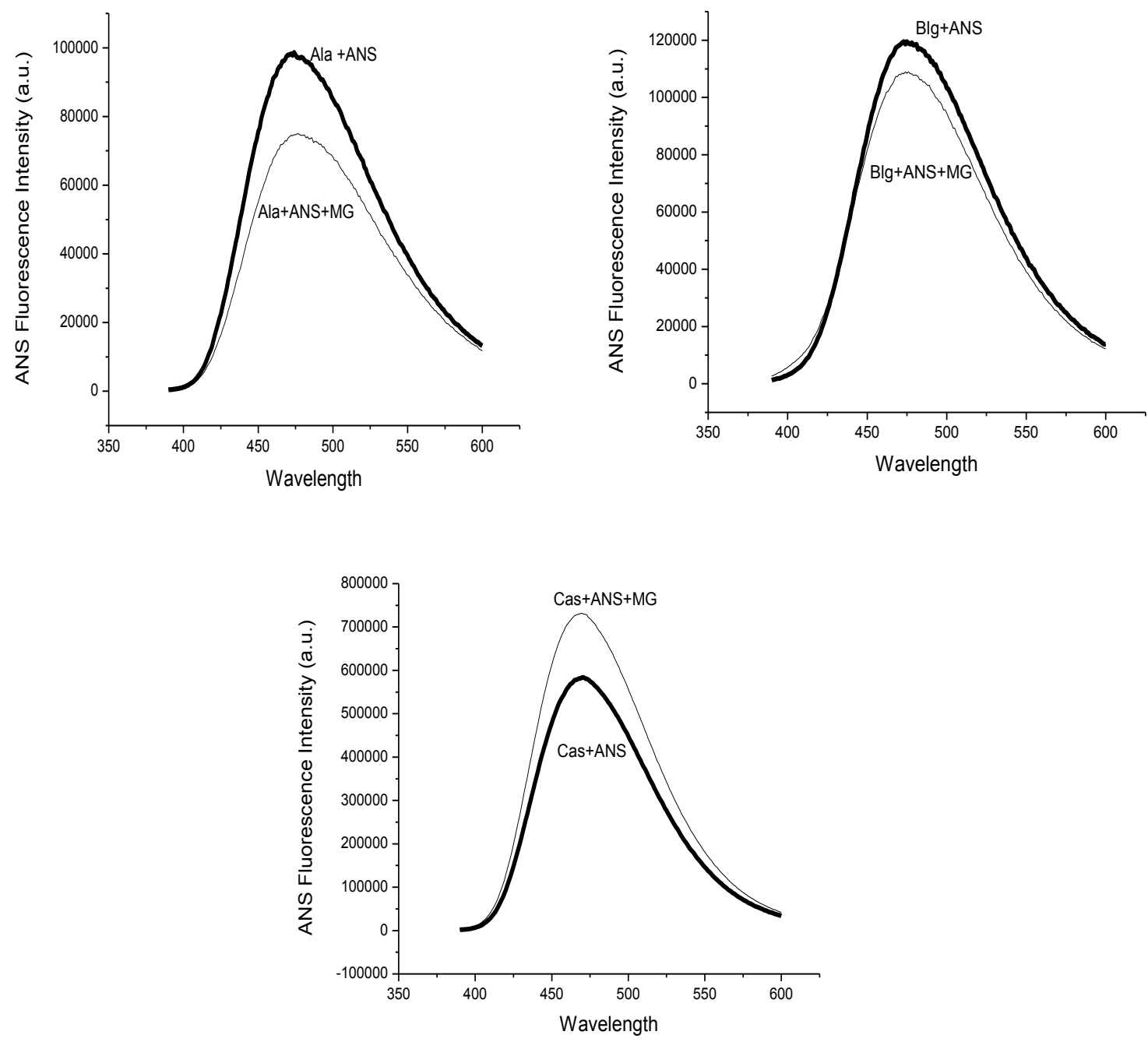

Figure 4: ANS fluorescence spectra of $10 \mu \mathrm{M}$ ALA, 10 $\mu \mathrm{M}$ BLG, and $10 \mu \mathrm{M}$ CAS bound to $20 \mu M$ ANS ( ), and the same in presence of $20 \mu \mathrm{M} M G($

Figure 4 shows the extrinsic ANS fluorescence spectra of the milk proteins in absence and presence of methylgyloxal. From the figure, it is clearly evident that upon incubation with methylglyoxal there is a slight decrease in the ANS fluorescence intensity of alpha lactalbumin and beta lactoglobulin and an increase in the intensity in case of alpha $\mathrm{S}$ casein compared to in 
absence of it. No change in peak position is observed. It indicates that upon binding to the sugar metabolite, solvent exposed hydrophobic patches of alpha lactalbumin and beta lactoglobulin are reduced such that hydrophobic patches get slightly buried. It thereby improves the stability of both the proteins. Increase of ANS fluorescence intensity in case of alpha S casein binding to methylglyoxal indicates that the protein adapts a more relaxed structure with increased solvent exposed hydrophobic patches.

\section{Dynamic Light scattering of milk proteins incubated with methylglyoxal:}

We also assessed the z-average hydrodynamic diameter of all the three milk proteins in absence and presence of varying concentrations of methylglyoxal after incubation at r.t. for 6 days. (Figure5). It is clearly evident that with increasing methylglyoxal concentration the hydrodynamic volume of the protein molecules decreases indicating a more compact structure of the proteins in presence of methylglyoxal. Taken together, all the above studies indicate that methylglyoxal prevents the milk proteins from denaturation.

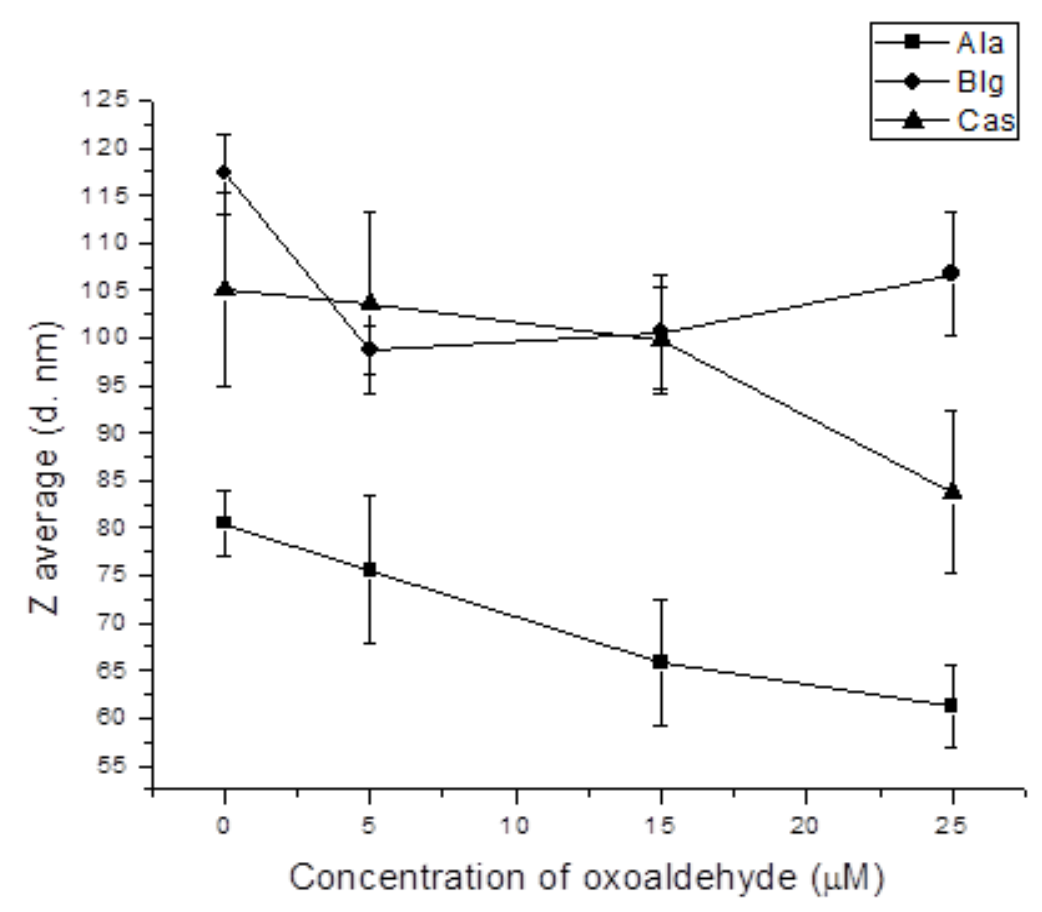

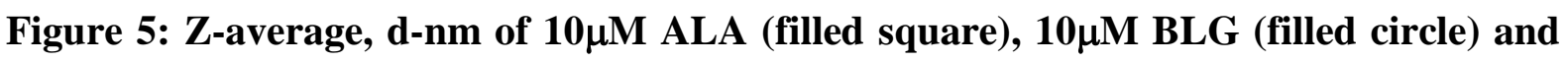
$10 \mu \mathrm{M}$ CAS (filled triangle) in absence and presence of different concentrations of MG.

\section{DISCUSSION:}

Earlier research suggests that glyoxal and methylglyoxal are environmental and/or bacterial toxin or metabolite $(13,14)$. Estimates of the concentrations of methylglyoxal and glyoxal in human blood plasma are in the range $100-120 \mathrm{nM}(15,16)$ and cellular concentrations of methylglyoxal $(1-5 \mu \mathrm{M})$ and glyoxal $(0.1-1 \mu \mathrm{M})(17)$. Studies investigating the effects of glyoxal and methylglyoxal on cultured cells, tissues and macromolecules using concentrations more than 10-fold higher than physiological concentration are likely to lead to toxicity. The 
use of methylglyoxal at millimolar concentrations to demonstrate impairment of insulin signaling, for example, is of unlikely physiological relevance (18). Still all studies by other groups have been conducted at very high doses of the sugar metabolites to allow sufficient interaction with biologics. Though most of the studies point to the harmful effects of $\mathrm{MG}$, there are a few studies that point that at millimolar concentrations and after prolonged hours of incubation, although the sugar metabolite crosslinks with proteins it imparts stability to the bound proteins instead of leading to its aggregation. Glycation of insulin by MGO at $\mathrm{mM}$ concentration reduces insulin fibril formation by blocking the formation of the seeding nuclei and leads to the formation of insulin native-like aggregates (6). At $\mathrm{mM}$ concentrations, the stability of MGO-treated hemoglobin was found to be higher compared to control hemoglobin and $\mathrm{H}_{2} \mathrm{O}_{2}$-mediated iron release and subsequent iron-mediated oxidation (Fenton) reactions were found to be lower in presence of MGO-treated hemoglobin compared to normal hemoglobin (10). All these studies were performed at very high doses of methylglyoxal.

Here, we have shown that methylglyoxal at significantly low doses (close to the physiological range) immediately prevent aggregation of milk proteins. Incubation of the proteins alone causes aggregation where we see changes in the secondary, tertiary and hydrodynamic volume of the proteins, but in presence of low doses of methylglyoxal it appears that the proteins remain stable. It appears that immediate exposure of the proteins to the sugar metabolites lead to shielding of the proteins against chemical or thermal stress thereby preventing aggregation of the same. Due to the fact that methylglyoxal exhibit anti-aggregating properties for proteins, at modestly low doses, they can be considered as potential therapeutic and/or formulating agents.

\section{ACKNOWLEDGEMENTS:}

This work has been financially supported by an independent research grant (SR/WOS-A/LS389/2016) awarded to JB from the Department of Science and Technology, Govt. of India. Technical assistance in this work provided by Subhajit Maity and Deepak Konar is appreciated. Thanks to Prof. A.S. Chakraborti, Prof. A. Lahiri and Prof. K.P. Das for providing support in different ways in this work.

\section{ABBREVIATIONS:}

MG methylglyoxal, DTT dithiothreitol, ALA alpha lactalbumin, BLG beta lactoglobulin, CAS alpha $\mathrm{S}$ casein.

\section{REFERENCES:}

1. Thornalley, P.J., Langborg, A., Minhas, H.S. (1999) Formation of glyoxal, methylglyoxaland 3-deoxyglucosone in the glycation of proteins by glucose, Biochem. J. 344, 109-116. 
2. McLellan, A.C., Thornalley, P.J., Benn, J. and Sonksen, P.H. (1994) Glyoxalase system inclinical diabetes mellitus and correlation with diabetic complications, Clin.Sci. 87, 21-29.

3. Oliveira, L.M.A., Lages, A., Gomes, R.A., Neves, H. and Familia, C. (2011) Insulin glycation bymethylglyoxal results in native-like aggregation and inhibition of fibrilformation, BMC Biochem. 12, 41.

4. Banerjee S, Maity S, Chakraborti AS (2016) Methylglyoxal-induced modification causes aggregation of myoglobin Spectrochim Acta A Mol Biomol Spectrosc. 155,110.

5. Bose, T., Bhattacherjee, A., Banerjee, S., and Chakraborti, A.S. (2013) Methylglyoxalinduced modifications of hemoglobin: structural and functional characteristics, Arch.Biochem. Biophys. 529 99-104.

6. Ahmed, N., Dobler, D., Dean, M., and Thornalley, P.J. (2005) Peptide mapping identifies hotspot site of modification in human serum albumin by methylglyoxal involved in ligand binding and esterase activity. J. Biol. Chem. 280, 5724-5732.

7. McKenzie, H.A. (1971) Milk proteins. Chem Mol Biol. 2, 117-367.

8. Banerjee S, Chakraborti AS. (2014) Structural alterations of hemoglobin and myoglobin by glyoxal: a comparative study. Int J Biol Macromol. 66,311-318.

9. Lo, T.W.C., Westwood, M.E., McLellan, A.C., Selwood, T., and Thornalley, P.J. (1994) Binding and modification of proteins by methylglyoxal under physiological conditions. A kinetic and mechanistic study with $\mathrm{N}$ alpha-acetylarginine, $\mathrm{N}$ alphaacetylcysteine, and $\mathrm{N}$ alpha-acetyllysine, and bovine serum albumin. J Biol Chem 269,32299-32305.

10. Priyankar Sen, Basir Ahmad, Gulam Rabbani, Rizwan Hasan Khan (2010) 2,2,2Trifluroethanol induces simultaneous increase in a-helicity and aggregation in alkaline unfolded state of bovine serum albumin. Int J Biol Macromol. 46, 250-254.

11. Das KP, Surewicz WK. (1995) Temperature-induced exposure of hydrophobic surfaces and its effect on the chaperone activity of alpha-crystalline. FEBS Lett, 369, 321-325.

12. Lee GJ, Roseman AM, Saibil HR, Vierling E. (1997) A small heat shock protein stably binds heat-denatured model substrates and can maintain a substrate in a foldingcompetent state. EMBO J., 16, 659-71.

13. Ahmed, N., Doble,r D., Dean, M., Thornalley, P.J. (2005) Peptide mapping identifies hotspot site of modification in human serum albumin by methylglyoxal involved in ligand binding and esterase activity. J Biol Chem. 280,5724-5732.

14. Aronsson, A.C., Mannervik, B. (1977) Characterization of glyoxalase I purified from pig erythrocytes by affinity chromatography. Biochem J. 165, 503-509. 
15. Cooper, R.A. Metabolism of methylglyoxal in microorganisms. (1984) Ann Rev Microbiol. 38, 49-68.

16. Beisswenger P.J., Howell, S. Touchette, A., Lal, S., Szwergold, B.S. (1999) Metformin reduces systemic methylglyoxal levels in type 2 diabetes. Diabetes. 48,198-202.

17. Strzinek, R.A., Scholes, V.E., Norton, S.J. (1972) Purification and Characterization of Liver Glyoxalase-I from Normal Mice and from Mice Bearing A Lymphosarcoma. Cancer Res. 32,2359-2364.

18. Dobler, D., Ahmed, N., Song, LJ., Eboigbodin, K.E., Thornalley, P.J. (2006) Increased dicarbonyl metabolism in endothelial cells in hyperglycemia induces anoikis and impairs angiogenesis by RGD and GFOGER motif modification. Diabetes. 55, 19611969.

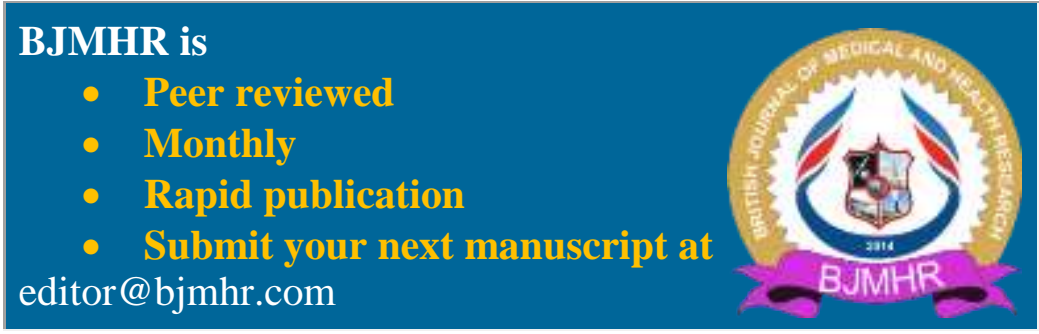

